\title{
IDENTIFIKASI BORAKS DAN FORMALIN PADA BAKSO DAGING DI LINGKUNGAN UNIVERSITAS MUHAMMADIYAH PALANGKARAYA
}

\author{
RABIATUL ADAWIYAH \\ Dosen Fakultas Ilmu Kesehatan Universitas Muhammadiyah Palangkaraya
}

\begin{abstract}
Food security is the responsibility of all parties that is the government's responsibility as manager of government which includes order, security and prosperous society. The responsibilities of employers or manufacturers as the economic actors that drive business improvement and provide the needs of the community and the consumers who uses the goods and services to meet their needs, especially food. The purpose of research is to determine the content of borax and formaldehyde in meatballs sold at the Muhammadiyah University of Palangkaraya. The method used is experimental research with laboratory approach that will be done with a series of try out.

The results of this study show that meatballs in the environment of Muhammadiyah University of Palangkaraya partially detectable formaldehyde but largely undetectable contain formaldehyde as a hazardous material for Health. While the study of borax is undetectable contain borax, it indicated by the colour of the flame is not green, after the flame test there is no change of colour on curcumin paper (still yellow ), after the colour test is done using curcumin paper.
\end{abstract}

Keywords : Food safety, hazardous materials, and health

\begin{abstract}
ABSTRAK
Keamanan makanan merupakan tanggung jawab semua pihak, yaitu tanggung jawab pemerintah selaku pengelola pemerintah yang meliputi ketertiban, keamanan dan sejahtera masyarkat. Tanggung jawab pengusaha (produsen) selaku pelaku ekonomi yang mendorong peningkatan usaha dan menyediakan kebutuhan masyarakat dan konsumen yang menggunakan barang dan jasa dalam memenuhi kebutuhan hidupnya terutama makanan. Tujuan penelitian adalah untuk mengetahui kandungan boraks dan formalin pada bakso daging yang dijual di lingkungan Universitas Muhammadiyah Palangkaraya. Metode yang digunakan dalam penelitian eksperimen atau percobaan (experiment research) dengan pendekatan laboratorium yang akan dilakukan dengan serangkaian percobaan. Hasil dari penelitian tersebut adalah bahwa bakso daging dilingkungan Universitas Muhammadiyah Palangkaraya sebagian terdeteksi formalin tetapi sebagian besar tidak terdeteksi mengandung formalin sebagai bahan berbahaya bagi Kesehatan. Sedangkan untuk penelitian borak tidak terdeteksi mengandung boraks yang ditunjukkan dengan warna nyala api tidak berwarna hijau, setelah dilakukan uji nyala api dan tidak adanya perubahan warna pada kertas kurkumin (tetap berwarna kuning), setelah dilakukan uji warna menggunakan kertas kurkumin.
\end{abstract}

Kata Kunci: keamanan pangan, bahan berbahaya, dan kesehatan.

\section{PENDAHULUAN}

Makanan merupakan salah satu kebutuhan dasar manusia yang terpenting dan juga merupakan faktor yang sangat esensial bagi pertumbuhan dan perkembangan manusia. Tetapi betapapun menariknya penampilan, lezat rasanya dan tinggi nilai gizinya, apabila tidak aman dikonsumsi, maka makanan tersebut tidak ada nilainya sama sekali (Winarno dan Rahayu, 1994).
Keamanan makanan merupakan tanggung jawab semua pihak, yaitu tanggung jawab pemerintah selaku pengelola pemerintah yang meliputi ketertiban, keamanan dan sejahtera masyarakat. Tanggung jawab pengusaha (produsen) selaku pelaku ekonomi yang mendorong peningkatan usaha dan menyediakan kebutuhan masyarakat dan konsumen yang menggunakan barang dan jasa dalam memenuhi kebutuhan hidupnya terutama makanan. 
Zaman dulu orang masih menggunakan zat tambahan alami dari tumbuh-tumbuhan dan hewan. Contonya untuk memberi rasa manis digunakan gula tebu dan madu, sedangkan daun suji, kunyit, gula merah dan daun jati ditambahkan untuk memberi warna pada makanan dan minuman dan garam bisa digunakan untuk mengawetkan ikan. Namun kini banyak produsen makanan yang mengganti zat tambahan natural dengan zat tambahan sintetis yang sifatnya lebih berbahaya bagi kesehatan manusia apabila dikonsumsi terus menerus dan berebihan.

Penambahan zat berbahaya sebagai pengawet makanan sangat marak digunakan pada saat ini. Pengawet biasanya ditambahkan pada makanan yang mudah rusak yang disukai sebagai medium tumbuhnya bakteri atau jamur, misalnya pada produk daging (bahan dasar daging) dan buah-buahan. Para pedagang biasanya memilih bahan pengawet yang harganya murah agar memperoleh keuntungan yang banyak, contoh adalah borak dan formalin.

Bahan Tambahan Pangan yang selanjutnya disingkat BTP adalah bahan yang ditambahkan kedalam pangan untuk mempengaruhi sifat atau bentuk pangan (Anonim,2012). Sejak pertengahan abad ke-20 ini, peranan bahan tambahan pangan (BTP) khususnya bahan pengawet menjadi semakin penting sejalan dengan kemajuan teknologi produksi bahan tambahan pangan sintetis (Cahyadi, 2012).

Pemerintah telah mengeluarkan peraturan tentang pelarangan penggunaan bahan berbahaya untuk pangan seperti misalnya penggunaan boraks sebagai Bahan Tambahan Pangan. Namun, sampai saat ini masih banyak ditemukan penyalahgunaan penggunaan boraks sebagai bahan untuk membuat pangan lebih kompak (kenyal) teksturnya dan sebagai pengawet (Rahayu \& Muliani, 2011). Boraks banyak digunakan dalam pembuatan berbagai makanan seperti bakso, mi basah, pisang molen, lemper, lontong, ketupat, pangsit dan siomay (Sri Sugiyatmi, 2006).

Salah satu makanan yang dalam pembuatannya diduga menggunakan boraks dan formalin adalah bakso daging, terbukti dibeberapa kota di Indonesia banyak para pedagang yang diketahui menggunakan boraks dan formalin sebagai bahan pengawet pada bakso dagingnya.

Pemakaian formalin sebagai bahan pengawet makanan dapat menyebabkan bahaya bagi kesehatan konsumen. Diantaranya adalah kerusakan otak, muntah-muntah, kerusakan hati, kerusakan ginjal, sakit perut akut, iritasi lambung, diare, dan bahkan bisa kencing darah. Jika dikomsumsi dalam jumlah besar bias mengakibatkan kejang-kejang, muntah darah dan kematian (Nuheti Yuliati, 2007).

Melihat maraknya minat masyarakat terhadap bakso daging dan berdasarkan kejadian tersebut di atas, maka peneliti merasa tertarik untuk melakukan penelitian dengen Judul "Identifikasi Boraks dan Formalin pada Bakso Daging di Lingkungan Universitas Muhammadiyah Palangkaraya ".

\section{Perumusan Masalah}

Berdasarkan identifikasi serta batasan masalah yang telah dikemukakan sebelumnya maka rumusan masalah dalam penelitian adalah Apakah ada bakso daging yang dijual oleh pedagang bakso di lingkungan Universitas Muhammadiyah Palangkaraya mengandung borak dan formalin? 


\section{Tujuan Penelitian}

Penelitian ini bertujuan untuk mengetahui kandungan boraks dan formalin pada bakso daging yang dijual di lingkungan Universitas Muhammadiyah Palangkaraya

\section{METODOLOGI}

\section{Tempat Penelitian dan Waktu Penelitian}

Kegiatan penelitian ini dilaksanakan di Laboratorium Fakultas IImu Kesehatan Universitas Muhammadiyah Palangkaraya. Waktu penelitian ini dimulai pada bulan Maret sampai dengan Juni 2014.

\section{Metode Penelitian}

Metode yang digunakan dalam penelitian eksperimen atau percobaan (experiment research) dengan pendekatan laboratorium yang akan dilakukan dengan serangkaian percobaan. Penelitian eksperimen atau percobaan (experiment research) adalah kegiatan yang bertujuan untuk mengetahui suatu gejala atau pengaruh yang timbul, sebagai akibat dari adanya perlakuan tertentu. (Notoadmodjo, 2005).

\section{Populasi dan Sampel}

Populasi pada penelitian ini adalah seluruh bakso daging yang dijual di lingkungan Universitas Muhammadiyah Palangkaraya. Sampel adalah sebagian yang diambil dari keseluruhan objek yang diteliti dianggap mewakili seluruh populasi. Teknik pengambilan sampel dalam penelitian ini yaitu menggunakan tekik Purposive Sampling. Pengambilan sampel secara Purposive Sampling didasarkan pada suatu pertimbangan tertentu yang dibuat peneliti sendiri.

\section{Alat dan Bahan}

Alat-alat yang digunakan dalam penelitian ini yaitu cawan porselen, korek api, oven, timbangan analitik, corong, Erlenmeyer, penjepit besi, mortir dan stamper, pipet tetes, bunsen, buret dan tanur, beaker glass $500 \mathrm{~mL}$, buret 10 $\mathrm{mL}$, gelas ukur $100 \mathrm{~mL}$, kapas, klem, kompor listrik, labu ukur $100 \mathrm{~mL}$, labu ukur $1000 \mathrm{~mL}$, labu ukur $250 \mathrm{~mL}$, neraca digital, pipet ukur $5 \mathrm{~mL}$, pipet volume $1 \mathrm{~mL}$, pipet volume $10 \mathrm{~mL}$, pipet volume 2 $\mathrm{mL}$, pipet volume $3 \mathrm{~mL}$, selang, seperangkat alat destilasi, seperangkat tabung reaksi, statif, stemper, tali sampage, dan termometer.

Bahan-bahan yang digunakan dalam penelitian ini yaitu sampel bakso daging, asam sulfat pekat $\left(\mathrm{H}_{2} \mathrm{SO}_{4}\right)$, asam klorida $(\mathrm{HCl})$ p.a, metanol p.a, natrium tetraborat p.a, kalsium karbonat $\left(\mathrm{CaCO}_{3}\right)$ p.a, turmerik powder, alkohol p.a, kertas saring (whatman 40), aquadest, kertas lakmus, formalin $37 \%$, asam fosfat $\left(\mathrm{H}_{3} \mathrm{PO}_{4}\right)$, dan asam kromatopat.

\section{Prosedur Kerja Boraks}

\section{Uji Kertas Kurkumin}

a. Membuat Kertas Kurkumin Timbang sebanyak 2 gram turmerik powder dan masukkan bersama $100 \mathrm{ml}$ etanol $80 \%$ kedalam Erlenmeyer $250 \mathrm{ml}$ lalu ditutup. Dikocok selama 5 menit setelah itu disaring menggunakan kertas saring. Celupkan kertas saring kedalam larutan tersebut, lalu kertas digantung untuk mengeringkan. Setelah 1 jam kertas dipotong dengan ukuran $6 \times 1 \mathrm{~cm}$ dan disimpan ditempat yang rapat dan terhindar dari cahaya (Anonim, 1999).

b. Uji Warna Kertas Kurkumin pada pengujian boraks Menurut Triastuti (2013), Prosedur 
uji warna kertas kurkumin pada pengujian boraks adalah sebagai berikut:

1) Preparasi Sampel

Sampel ditimbang sebanyak 50 gram dan di oven pada suhu $120^{\circ} \mathrm{C}$, setelah kering di tambahkan dengan 10 gram kalsium karbonat. Kemudian masukkan ke dalam tanur hingga menjadi abu selama 6 jam dan dinginkan.

2) Membuat Kontrol Positif

Baku boraks dicampurkan kedalam blanko lalu di oven pada suhu $120^{\circ} \mathrm{C}$, setelah itu ditambahkan dengan 10 gram kalsium karbonat kemudian masukkan kedalam tanur hingga menjadi abu selama 6 jam dan dinginkan. Abu kemudian tambahkan 3 $\mathrm{ml}$ asam klorida $10 \%$, celupkan kertas kurkumin. Kertas yang mulanya berwarna kuning berubah menjadi merah kecoklatan dan digunakan sebagai baku positif.

3) Identifikasi Boraks pada Sampel

Abu dari sampel kemudian ditambahkan $3 \mathrm{ml}$ asam klorida $10 \%$, celupkan kertas kurkumin. Bila di dalam sampel terdapat boraks, kertas kurkumin yang berwarna kuning menjadi berwarna merah kecoklatan.

\section{Uji Nyala Api}

a. Preparasi Sampel

Sampel ditimbang sebanyak 10 gram di oven pada suhu $120^{\circ} \mathrm{C}$ selama 6 jam, kemudian sampel diarangkan.

b. Identifikasi Boraks pada Sampel

Sampel yang telah menjadi arang ditambahkan $1 \mathrm{ml}$ asam sulfat pekat dan
$5 \mathrm{ml}$ metanol dalam cawan porselen dan dinyalakan, bila timbul nyala yang pinggirnya hijau maka menandakan adanya boraks (Vogel, 1985).

c. Membuat Kontrol Positif

Baku boraks dicampurkan kedalam blanko di oven pada suhu $120^{\circ} \mathrm{C}$ selama 6 jam, kemudian diarangkan. Setelah menjadi arang ditambahkan $1 \mathrm{ml}$ asam sulfat pekat dan $5 \mathrm{ml}$ metanol, kemudian dibakar nyala yang dihasilkan berwarna hijau dipinggir dan digunakan sebagai baku positif.

\section{Limit of Detection (LOD) Boraks pada}

\section{Bakso Daging}

a. Pembuatan Baku Induk 2500 ppm:

Timbang sebanyak 2,5 gram boraks

masukkan kedalam labu tentukur 1000

$\mathrm{ml}$. Larutkan dengan aquadest hingga $1000 \mathrm{ml}$.

b. Membuat baku seri 1250,1000,750,500,250 dan 200 ppm: LOD Boraks pada Siomay Metode Kertas Kurkumin:

Pipet sebanyak 25,20,15,10,5 dan $4 \mathrm{ml}$ dari larutan baku induk masing-masing kedalam 50 gram sampel. Di oven pada suhu $120^{\circ} \mathrm{C}$, setelah kering ditambahkan dengan $10 \mathrm{ml} \mathrm{CaCO}$, 10\%. Kemudian masukkan ke dalam tanur hingga menjadi abu selama 6 jam dan dinginkan. Abu kemudian ditambahkan $6 \mathrm{ml}$ asam klorida $10 \%$. Celupkan kertas kurkumin.

LOD Boraks pada bakso daging Metode Uji Nyala:

Pipet sebanyak 5, 4, 3, 2 dan $1 \mathrm{ml}$ dari larutan baku induk masing-masing 
kedalam 10 gram sampel, lalu di oven pada suhu $120^{\circ} \mathrm{C}$ selama 6 jam kemudian diarangkan. Setelah menjadi arang ditambahkan $1 \mathrm{ml} \mathrm{H}_{2} \mathrm{SO}_{4}$ pekat dan $5 \mathrm{ml}$ metanol kemudian dinyalakan.

\section{Prosedur Kerja Formalin}

\section{Pembuatan Larutan Pereaksi Asam Kromatropat}

Pereaksi dibuat dengan cara melarutkan $0,5 \%$ asam kromatropat dalam asam sulfat 72\% (Rohman, 2005).

2. Pembuatan Baku Induk Larutan Formalin 370 ppm (part per million)

a) Diambil $1 \mathrm{~mL}$ larutan formalin dari sedian formalin $37 \%$.

b) Dimasukan ke dalam labu ukur 1000 $\mathrm{mL}$, ditambahkan aquades hingga tepat batas dan kocok hingga homogen.

\section{Pembuatan Baku Seri Formalin}

Formalin 0 ppm (kontrol negatif) $=$ Aquades $100 \mathrm{~mL}$

\section{Destilasi Sampel}

Sebanyak 100 gram sampel bakso daging dicampur dengan $100 \mathrm{~mL}$ air yang ditambahkan sedikit demi sedikit sambil digerus sampai halus dan/atau homogen. Gerusan dipindah ke dalam labu destilasi, di asamkan dengan asam fosfat, dan ditambah $1 \mathrm{~mL}$ asam fosfat berlebih. Labu destilasi selanjutnya dihubungkan dengan pendingin dan selanjutnya di destilasi. Hasil destilasi ditampung (Rohman, 2005).

5. Identifikasi Formalin (Sampel Uji) dengan Pereaksi Asam Kromatropat

Sebanyak $5 \mathrm{~mL}$ peraeaksi asam kromatofat dimasukan ke dalam tabung reaksi, ditambah $1 \mathrm{~mL}$ larutan hasil destilasi sambil diaduk.
Larutan di masukan ke dalam penangas air mendidih selama 15 menit dan diamati perubahan warna yang terjadi. Adanya formaldehid ditunjukan dengan timbulnya warna ungu terang sampai ungu tua (Rohman, 2005).

\section{HASIL DAN PEMBAHASAN Boraks}

Hasil Penelitian identifikasi boraks pada bakso daging di lingkungan Universitas Muhammadiyah Palangkaraya pertama kali dilakukan menggunakan uji nyala api. Hasil identifikasi pada baku sodium tetraborat dan 3 (tiga) sampel bakso daging disajikan pada tabel 1 .

Penelitian identifikasi boraks pada bakso daging dilanjutkan dengan metode kedua dilakukan menggunakan uji warna dengan kertas kurkumin. Hasil identifikasi pada baku sodium tetraborat dan 3 (tiga) sampel bakso daging disajikan pada tabel 2.

Hasil penelitian identifikasi boraks di atas pada bakso daging di lingkungan Universitas Muhammadiyah Palangkaraya ini menggunakan metode uji nyala api (Svehla, 1985) dan metode reaksi warna menggunakan kertas kurkumin (Triastuti et al., 2013). Sampel yang digunakan adalah sampel bakso daging yang diambil dari 3 pedagang bakso daging di lingkungan Universitas Muhammadiyah Palangkaraya meskipun berbeda-beda tempat produksinya.

Berdasarkan tabel 2. bahwa pengujian baku sodium tetraborat (kontrol positif) pada metode uji nyala api menunjukkan bahwa sampel yang telah menjadi arang kemudian ditambahkan dengan sodium tetraborat, setelah itu ditambahkan $1 \mathrm{ml}$ asam sulfat pekat dan $5 \mathrm{ml}$ 
metanol kemudian dibakar. Hasil yang didapat pada saat pembakaran sampel mengalami nyala api menjadi biru dengan pinggiran hijau, hal ini terjadi karena terbentuknya senyawa metil borat.

Sampel 1, 2 dan 3 dengan metode uji nyala api sampel menunjukkan negatif mengandung boraks yang ditandai dengan tidak terbentuk nyala api warna biru pinggiran hijau. Warna nyala api yang dihasilkan dari sampel 1, 2 dan 3 berupa merah orange.

Identifikasi boraks pada bakso daging setelah dilakukan menggunakan metode uji nyala api dan menghasilkan negatif mengandung boraks, maka uji dilanjutkan menggunakan uji warna dengan kertas kurkumin. Berdasarkan tabel 4.2. bahwa pengujian baku sodium tetraborat (kontrol positif) pada metode uji warna menggunakan kertas kurkumin menunjukkan bahwa sodium tetraborat ditambahkan ke dalam sampel, kemudian dimasukkan ke dalam tanur listrik hingga menjadi abu, setelah menjadi abu

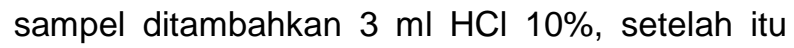
dilakukan pengecekan $\mathrm{pH}$ dengan menggunakan indikator $\mathrm{pH}$. Kemudian mencelupkan kertas kurkumin ke dalam sampel dan menghasilkan perubahan warna kertas kurkumin dari warna kuning menjadi warna merah kecoklatan. Hal ini terjadi karena adanya reaksi antara kurkumin dan boraks sehingga membentuk senyawa komplek yang berwarna merah kecoklatan yang bernama senyawa rosasianin (Roth dan Blaschke, 1988).

Identifikasi boraks terhadap bakso daging pada sampel 1, 2 dan 3 dengan metode uji warna dengan kertas kurkumin menghasilkan bahwa bakso dag tersebut negatif mengandung boraks yang ditandai dengan tidak terjadi perubahan warna dari kertas kurkumin tersebut (kertas kurkumin tetap berwarna kuning)

Berdasarkan hasil identifikasi boraks ini dilakukan pengujian limit of detection (LOD) pada baku boraks dengan cara membuat baku induk sodium tetraborat dengan konsentrasi 2500 ppm, yang kemudian dibuat baku serinya dengan berbagai konsentrasi yaitu 1.250 ppm, 1000 ppm, 750 ppm, 500 ppm, 250 ppm. Pada konsentrasi 250 ppm warna merah kecoklatan mulai samar dan hampir tidak terlihat setelah didiamkan selama 5 menit. Hal ini menyatakan bahwa LOD sodium tetraborat adalah 250 ppm. Jadi, nilai LOD metode identifikasi boraks dengan kertas kurkumin sebesar 250 ppm. Dari hasil LOD dapat disimpulkan bahwa pada konsentrasi 250 ppm merupakan batas terkecil analit dalam sampel yang dapat dideteksi atau yang masih memberikan respon warna kertas kurkumin sedikit merah kecoklatan. Sedangkan untuk dibawah konsentrasi 250 ppm kertas kurkumin tidak memberikan respon atau warna yang ditimbulkan tetap berwarna kuning.

Berdasarkan Permenkes Republik Indonesia Nomor 033 tahun 2012 bahwa boraks adalah salah satu bahan berbahaya yang dilarang digunakan sebagai bahan tambahan pangan. Pada penelitian ini semua sampel bakso daging di lingkungan Universitas Muhammadiyah palangkaraya tidak terdeteksi mengandung boraks dengan menggunakan uji nyala api dan uji warna dengan kertas kurkumin.

\section{Formalin}

Pada penelitian Identifikasi formalin pada bakso daging, salah satu uji analisis secara kualitatif adalah dengan cara uji Identifikasi ini di lakukan dengan pereaksi asam kromatropat. 
Sebelum dilakukan identifikasi formalin terlebih dahulu yang dilakukan adalah membuat uji batas (limit test) untuk menentukan LOD (Limit Of Detection) formalin pada bakso daging. Uji batas dilakukan dengan cara membuat baku formalin dalam beberapa konsentrasi yaitu 3,7 ppm, 4,4 ppm, 7,4 ppm, 11,1 ppm, 18,5 ppm, dan 37,0 ppm.

Uji LOD di lakukan dengan dua persi yaitu menggunakan sampel dan tidak menggunakan sampel, sampel yang dianggap tidak menggandung formalin direndam selama semalam agar mengetahui pada LOD berapa bakso daging yang mengandung formalin sudah mulai tidak ada. Bakso daging yang direndam dilakukan penimbangan sama dengan perlakuan sampel yaitu 100 gram di masukkan kedalam erlenmeyer lalu direndam dengan ppm yang telah dibuat.

Bakso daging yang telah direndam dikeringkan sebentar lalu di masukkan kedalam labu destilasi dengan menambahkan aquadest kurang lebih $200 \mathrm{ml}$ dan diasamkan dengan asam fosfat $1 \mathrm{ml}$. kemudian di destilasi sampai uap air mengalir, setelah itu hasil destilat dimasukkan kedalam tabung reaksi. Ambil $1 \mathrm{ml}$ hasil destilasi lalu di tambahkan pereaksi $5 \mathrm{ml}$ homogenkan dan dimasukkan kepenangas air selama 15 menit, amati perubahan warna yang terjadi. Dari pengujian uji batas untuk menentukan LOD formalin pada bakso daging maka didapatkan hasil pada tabel 3.

Hasil uji batas (limit test) formalin pada bakso daging, pada konsentrasi 4,4 ppm warna ungu sudah mulai pudar hampir tidak terlihat. Hal ini menyatakan LOD (Limit Of Detection) formalin pada bakso daging berkisar antara 4,4 ppm.
Sehingga konsentrasi formalin pada bakso daging dibawah 4,4 ppm, maka tidak akan terdeteksi. Jadi, batas deteksi formalin dalam bakso daging yang digunakan dalam penelitian ini adalah 4,4 ppm.

Identifikasi formalin pada bakso daging dalam penelitian ini dilakukan pada bakso daging yang dijual di Lingkungan Universitas Muhamadiyah Palangkaraya. Sampel yang di ambil di tiga tempat berbeda, masing-masing sampel yang sudah di beli di potong kecil lalu di lakukan penimbangan sebanyak 100 gram, kemudian dimasukkan ke labu destilasi, di tambahkan aquadest kurang lebih $200 \mathrm{ml}$ dan 1 $\mathrm{ml}$ asam fosfat.

Destilasi merupakan teknik memisahkan dua atau lebih komponen yang memiliki perbedaan titik didih yang jauh. Suatu campuran dapat dipisahkan dengan destilasi biasa ini untuk memperoleh senyawa murninya. Senyawasenyawa yang terdapat dalam campuran akan menguap pada saat mencapai titik didih masingmasing. Hasil destilat ditampung didalam beaker glass dan di pindahkan kedalam tabung reaksi.

Uji Identifikasi formalin terhadap bakso daging di lakukan dengan metode reaksi warna menggunakan asam kromatropat $0,5 \%$. Proses identifikasi dengan reaksi warna di lakukan dengan cara mereaksikan $5 \mathrm{ml}$ asam kromatropat dengan hasil destilat dan kemudian di panaskan didalam penangas air selama 15 menit. Selama proses pemanasan tabung reaksi harus dalam keadaan tertutup menggunakan kapas bebas lemak. Setelah beberapa menit pemanasan amati hasil perubahan warna yang terjadi, apabila larutan yang di uji berwarna ungu pekat atau ungu 
terang berarti sampel tersebut di nyatakan terdeteksi mengandung formalin.

Pembentukan warna ungu pada asam kromatropat dan formalin adalah apabila senyawa tersebut dipanaskan dengan asam kromatropatdalam larutan asam sulfat pekat akan membentuk warna violet. Reaksi ini terjadi berdasarkan kondensasi formaldehida dengan sistem aromatik dari asam kromatropat, membentuk senyawa berwarna (3,4,5,6dibenzoxanthylium). Pewarnaan disebabkan terbentuknya ion karbenium - oksonium yang stabil karena mesomeri (HernaJulinSimanjuntak)

Pengujian identifikasi formalin pada bakso daging yang di jual di tiga tempat di lingkungan universitas muhammadiyah palangkaraya di peroleh hasil pada tabel 4
Hasil penelitian pada tabel 4. adalah sampel 1 memunjukan terdeteksi menggandung formalin dengan menunjukan warna ungu. Maka dari identifikasi formalin pada sampel penelitian dinyatakan terdeteksi mengadung formalin. Sedangkan sampel 2 dan sampel 3 tidak memunjukan terdeteksi menggandung formalin karena tidak menunjukan warna ungu melainkan berwarna kuning jernih.

Hasil pengujian kedua pada sampel dengan proses pengujian yang sama yaitu dengan mendestilasi bakso daging dan hasil destilat di tampung lalu dilakukan pengujian dengan asam kromatropat0,5\% dan di panaskan di penangas air. Hasil menunjukan bahwa bakso daging sampel 1 terdeteksi mengandung formalin sedangkan sampel 2 dan sempal 3 tidak terdeteksi mengandung formalin.

Tabel 1. Hasil identifikasi boraks pada bakso menggunakan uji nyala api

\begin{tabular}{|c|l|l|c|}
\hline No. & \multicolumn{1}{|c|}{ Sampel } & \multicolumn{1}{|c|}{ Warna Nyala Api } & Hasil pengamatan \\
\hline 1. & Baku sodium tetraborat (kontrol positif) & Biru dengan pinggiran hijau & Positif \\
\hline 2. & Sampel 1 & Merah orange & Negatif \\
\hline 3. & Sampel 2 & Merah orange & Negatif \\
\hline 4. & Sampel 3 & Merah orange & Negatif \\
\hline
\end{tabular}

Tabel 2. Hasil identifikasi boraks pada bakso daging menggunakan uji warna dengan kertas kurkumin

\begin{tabular}{|c|l|c|c|}
\hline No. & Sampel & Kertas kurkumin & Hasil pengamatan \\
\hline 1. & Baku sodium tetraborat (kontrol positif) & warna kuning menjadi merah & kecoklatan \\
\hline 2. & Sampel 1 & $\begin{array}{c}\text { Tetap warna kuning (tidak terjadi } \\
\text { perubahan merah kecoklatan) }\end{array}$ & Negatif \\
\hline 3. & Sampel 1 & $\begin{array}{c}\text { Tetap warna kuning (tidak terjadi } \\
\text { perubahan merah kecoklatan) }\end{array}$ & Negatif \\
\hline 4. & Sampel 1 & $\begin{array}{c}\text { Tetap warna kuning (tidak terjadi } \\
\text { perubahan merah kecoklatan) }\end{array}$ & Negatif \\
\hline
\end{tabular}

Tabel 3. Hasil Uji Batas Formalin Pada Bakso Daging

\begin{tabular}{|c|c|c|}
\hline No. & Konsentrasi (ppm) & +Asam Kromatropat \\
\hline 1. & $37,0 \mathrm{ppm}$ & Ungu \\
\hline 2. & $18,5 \mathrm{ppm}$ & Ungu \\
\hline 3. & $11,1 \mathrm{ppm}$ & Ungu \\
\hline 4. & $7,4 \mathrm{ppm}$ & Ungu memudar \\
\hline 5. & $4,4 \mathrm{ppm}$ & Ungu tipis \\
\hline 6. & $3,7 \mathrm{ppm}$ & Kuning jernih \\
\hline
\end{tabular}


Tabel 4. Hasil Identifikasi Formalin Pada Bakso Daging

\begin{tabular}{|c|c|c|c|c|}
\hline No & Sampel & + Asam Kromatropat & Keterangan & Hasil \\
\hline 1. & Sampel 1 & Kuning Jernih & Terdeteksi & Positif \\
\hline 2. & Sampel 2 & Kuning Jernih & Tidak Terdeteksi & Negatif \\
\hline 3. & Sampel 2 & Kuning Jernih & Tidak Terdeteksi & Negatif \\
\hline
\end{tabular}

\section{KESIMPULAN DAN SARAN}

\section{Kesimpulan}

Berdasarkan hasil penelitian dapat ditarik kesimpulan bahwa bakso daging dilingkungan Universitas Muhammadiyah Palangkaraya sebagian terdeteksi formalin tetapi sebagian besar tidak terdeteksi mengandung formalin sebagai bahan berbahaya bagi Kesehatan. Sedangkan untuk penelitian borak tidak terdeteksi mengandung boraks yang ditunjukkan dengan warna nyala api tidak berwarna hijau, setelah dilakukan uji nyala api dan tidak adanya perubahan warna pada kertas kurkumin (tetap berwarna kuning), setelah dilakukan uji warna menggunakan kertas kurkumin.

\section{Saran}

Saran yang dapat diberikan adalah :

1. Perlu dilakukan penelitian lebih lanjut tentang bahan tambahan lain yang dilarang ditambahkan pada proses pembuatan bakso daging..

2. Perlu dilakukan penelitian lebih lanjut tentang identifikasi formalin dan boraks pada bakso daging.

\section{DAFTAR PUSTAKA}

BPOM RI. 2008. Formalin (Larutan Formaldehid). http://www.pom.go.id/files/ formalin.pdf [Diakses pada tanggal 5 Maret 2013].

Brady, E. J. 2008. Kimia Universitas Asas dan Struktur Jilid Satu. Bina Rupa Aksara. Jakarta.
Chang, R. 2005. Kimia Dasar Konsep-Konsep Inti Edisi Ketiga Jilid 1. Erlangga. Jakarta.

Departemen Kesehatan RI. 1979. Farmakope Indonesia Ed. III. Depkes RI. Jakarta.

Departemen Kesehatan RI. 2012. Peraturan Menteri Kesehatan Republik Indonesia Nomor 033 Tahun 2012, Tentang Bahan Tambahan Pangan. Depkes RI. Jakarta.

Hanny, C.W., N. Mulyono, dan F.A. Afandi. 2012. Bahan Tambahan Pangan Pengawet. IPB. Bogor.

Manado Post. 16 Agustus 2012. Daging Formalin Dijual di Swalayan. Manado Post News. http://www.manadopost.co.id/index.php? mib=berita.detail\& $\mathrm{id}=114562$ [Diakses pada tanggal 28 Januari 2013].

Nasir, A., A. Mubith, dan M.E. Ideputri, 2011. Buku Ajar Metodologi Penelitian Kesehatan.Nuha Medika.Yogyakarta.

Nurfaisyah, 2011. Bahan Tambahan Makanan (Pengawet) dan Analisisnya secara Kualitatif dan Kuantitatif. http://nurfaisyah.web.id/bahan-

tambahan- makanan-pengawet-dananalisisnya-secara-kualitatif-dan-

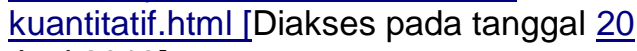
Juni 2013].

Riyadi, W. 2009. Validasi Metode Analisis. http://www.chem-is-try.org/artikel kimia/kimia analisis/validasi-metode-

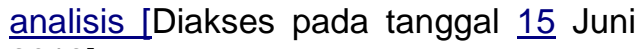
2013].

Undang-Undang Republik Indonesia Nomor 18 Tahun 2012 tentang Pangan. 